\title{
Comparison of the Grip Strength Using the Martin-Vigorimeter and the JAMAR-Dynamometer: Establishment of Normal Values
}

\author{
SINA NEUMANN ${ }^{1,2,3}$, SEBASTIAN KWISDA ${ }^{4}$, CHRISTIAN KRETTEK $^{2}$ and RALPH GAULKE KH $^{1,2}$ \\ ${ }^{1}$ Section Upper Extremity, Foot- and Rheuma Surgery, Department for Traumatology, \\ Medical School Hannover (MHH), Hannover, Germany; \\ ${ }^{2}$ Department of Traumatology, Medical School Hannover (MHH), Hannover, Germany; \\ ${ }^{3}$ Department of Oral and Maxillofacial Surgery, \\ University Medical Center Hamburg-Eppendorf, Hamburg, Germany; \\ ${ }^{4}$ Department for Orthopaedic Surgery, Schulthess Clinic, Zurich, Switzerland
}

\begin{abstract}
Background/Aim: The JAMAR-Dynamometer and the Martin-Vigorimeter are frequently used tools in a hand surgeon's daily routine. This survey is primarily concerned with the establishment of valid conversion factors for measured values of both instruments, as well as the investigation of influence of anatomical characteristics and age and sex on maximal measured grip strength. Patients and Methods: We registered anamnestic data and specific anatomical conditions in 339 patients, maximal grip strength was measured using all notches of both instruments. Results: We found moderate to very high correlation comparing all 28 settings in both instruments. The influence of the hand's anatomy on the grip strength was greater using the JAMARDynamometer than it was using the Martin-Vigorimeter. Conclusion: The high reproducibility allowed us to calculate multiplying factors for the conversion of measured data for all settings of both tools. Therefore, the amount of data for meta-analyses relating to hand surgical issues can be significantly increased.
\end{abstract}

Grip strength measurements are routinely used in clinical settings. They are an indicator for the efficacy of hand surgical therapies and serve as outcome control (1-4). The most commonly used instruments for measuring grip

This article is freely accessible online.

Correspondence to: Dr. Ralph Gaulke, Department for Traumatology, Medical School Hannover (MHH), Carl-NeubergStraße 1, 30625 Hannover, Germany. Tel: +49 5115322026, e-mail: gaulke.ralph@mh-hannover.de

Key Words: JAMAR, Martin, grip strength, comparison, conversion factor. strength are the JAMAR-Dynamometer and the MartinVigorimeter. The former is a hydraulic instrument measuring the isometric strength in kilograms, the latter measures the force of compression in kilo pascal by means of a compressible rubber ball $(5,6)$. Numerous studies have investigated the reliability of both instruments in different populations $(2,4,7-11)$. However, to the best of our knowledge, only a few studies directly compare these two instruments. Sipers et al. compared the applicability and the test-retest reliability of both instruments in geriatric patients and found no significant difference in test-retest reliability. Handgrip strength showed a strong correlation between the first and second measurement in both instruments (1). Molenaar et al. examined reliability and accuracy of both instruments in 104 children under 12. Their results indicate that both instruments are reliable for measuring grip strength within this population. The Lode dynamometer (equivalent to JAMAR-Dynamometer) detected small differences in grip strength more accurately (12). Desrosiers et al. analyzed a population of 360 randomly selected healthy, elderly patients and while they found a good correlation between the respective results of both instruments, they did not determine a conversion factor (13).

To recap, most scientific studies have only used one of the two methods. Moreover, measuring has mostly been limited to one level or one size of balloon, respectively $(4,14-16)$. Using just one level per instrument to determine grip strength impairs optimal comparability of the results given that a couple of studies have found a correlation between morphological parameters of the hand and lower arm and maximum grip strength, depending on the level of the instrument or the size of the balloon used (17-19). Until recently, it has been impossible to compare results of studies that use just one of the two instruments in any setting with results of studies using the other. Therefore, the primary aim 
of this study was to determine conversion factors for the values of both instruments for all levels or sizes and to enable the comparison of the results of numerous studies, and thereby enlarging the amount of data available for metaanalyses within the field of hand surgery. We also aimed to show anatomical influences on the results in order to make informed recommendations about which settings to use on which instrument regarding specific hand sizes, and to determine the influence of age and sex on the results.

\section{Patients and Methods}

This survey was authorised by the local ethics committee (Nr. 14982012). Each patient in our study group signed a written consent form.

Patients. We randomly included all patients between the ages of 1490 years with healthy and symptom free hands, who were treated in the Department of Traumatology over a period of three months. We excluded patients with injuries, deformities, degenerative or inflammatory functional limitations of the upper extremities as well as patients with dementia to minimise any bias that could influence correlation. Since the study design contained many subgroup analyses and focused on a correlation between the two machines, we desisted from conducting a power analysis and chose a sample size following the study of Desrosiers et al. (13).

Grip strength analysis. We registered anamnestic data that could influence our measurements such as: age, sex, handedness and current occupation. Patients were divided into five different age categories $(<20 / 20-40 / 41-60 / 61-80 />80$ years $)$. Specific anatomical conditions were measured in all patients: circumference of the forearm $15 \mathrm{~cm}$ distal of the radial epicondyle, length of the palm (from the palmar fold of the wrist to the fold of the metacarpophalangeal joint of the middle finger), length of the hand (from the palmar fold of the wrist to the tip of the middle finger), the hand's circumference without the thumb and the width of the palm (from the ulnar margin of the metacarpophalangeal joint of the thumb to the ulnar border of the palm). The measurements of the grip strength were determined by means of the JAMARDynamometer (J A Preston Corporation, New York, USA) using all five notches and by means of the Martin-Balloon-Vigorimeter (Firma Gebrüder Martin, Tuttlingen, Germany) using all three ball sizes (Figure 1). All of the instruments were checked for damages, inspected for proper function and calibrated. Each patient was shown the correct handling and positioning of the instruments: Patients were asked to sit straight, with the upper arm in a neutral position and a $90^{\circ}$ flexion of the elbow. The forearm was held in neutral position and the wrist at a 0 to $30^{\circ}$ extension. The instrument was held freely: neither the hand nor the forearm was allowed to rest on a surface. To minimise signs of fatigue we included resting periods after each trial. Additionally, to avoid systematic errors we randomised the sequence in which we carried out the trials. Sequence one: JAMAR notch 1 - Martin balloon 2 - JAMAR notch 2 - Martin balloon 3 - JAMAR notch 3 - Martin balloon 5 JAMAR notch 4 - JAMAR notch 5. Sequence two: Martin balloon 2 - JAMAR notch 1 - Martin balloon 3 - JAMAR notch 2 JAMAR notch 3 - Martin balloon 5 - JAMAR notch 4 - JAMAR notch 5 . Afterwards, we randomised the side to be tested first. All measurements were repeated three times on each side.
Statistical analysis. The data were processed with Excel 2011 (Microsoft Corporation, Redmond, USA) and GraphPad Prism 6.0 (GraphPad Software, Inc., La Jolla, USA). We calculated the median values and the interquartile range $(25$ th -75 th percentile) as data proved to be non-parametric. We calculated the conversion factors by forming the quotients of the measured values for all notches and determined mean values and standard deviations. The influence of anatomical characteristics on the grip strength was determined using a Spearman rank correlation to minimise the effect of outlying data and non-parametric distribution. The level of significance was placed at $p<0.05$. The interpretation of the correlation coefficient followed Mukaka (20), who distinguished low $(\mathrm{r}<0.5)$, moderate $(\mathrm{r}<0.7)$, high $(r<0.9)$ and very high $(r>0.9)$ correlation.

\section{Results}

Subject characteristics. Three hundred and thirty-nine patients (132 women/207 men) aged between 14-88 years (mean 49 18.4 years) were included. Our study group primarily comprised age groups 41-60 years $(n=129), 61-80$ years $(n=103)$ and $20-40$ years $(n=85) .91 .45 \%$ of all patients were right-handed, $6.19 \%$ were left-handed and $2.36 \%$ had no dominant hand (Table I).

Grip strength results. The median maximum grip strength in men was $79 \%$ greater than in women using the JAMARDynamometer, and it was $38 \%$ greater using the MartinVigorimeter $(19.7 \mathrm{~kg}$ women/35.3 kg men and $53.3 \mathrm{kPa}$ women/73.3 $\mathrm{kPa}$ men). Overall, we found very high correlations between the measured grip strength of the dominant hand using notch 2 of the JAMAR-Dynamometer and balloon 5 of the Martin-Vigorimeter $(\mathrm{r}=0.86$ ), as well as between notch 3 of the JAMAR-Dynamometer and balloon 5 of the Martin-Vigorimeter $(\mathrm{r}=0.86)$. Within the measurements of one instrument, we found a very high correlation between measured grip strength using notch 3 and 4 of the JAMARDynamometers $(r=0.97)$, as well as between balloon size 3 and 5 of the Martin-Vigorimeter $(r=0.92)$ (Table II). We calculated multiplying factors for the correlation of all measured data for all settings on both instruments (Table III). With regards to the anatomical characteristics we found a moderate correlation between the maximum grip strength and the hand's circumference without the thumb of the dominant hand using the JAMAR-Dynamometer $(r=0.64)$. We also found a moderate correlation $(r=0.65)$ between the width of the palm and the circumference of the forearm to the maximal grip strength measured with the JAMAR-Dynamometer. Both, the length of the palm and the length of the dominant hand had a moderate correlation with the maximal grip strength using the JAMAR-Dynamometer $(\mathrm{r}=0.52$ and 0.55 , respectively). Using the Martin-Vigorimeter, the maximal grip strength showed only a low correlation to the anatomical characteristics $(\mathrm{r}<0.5)$. The highest correlation was found with the circumference of the forearm $(r=0.49)$ (Figure 2). At least $64 \%$ of patients reached the maximal grip strength when 
A

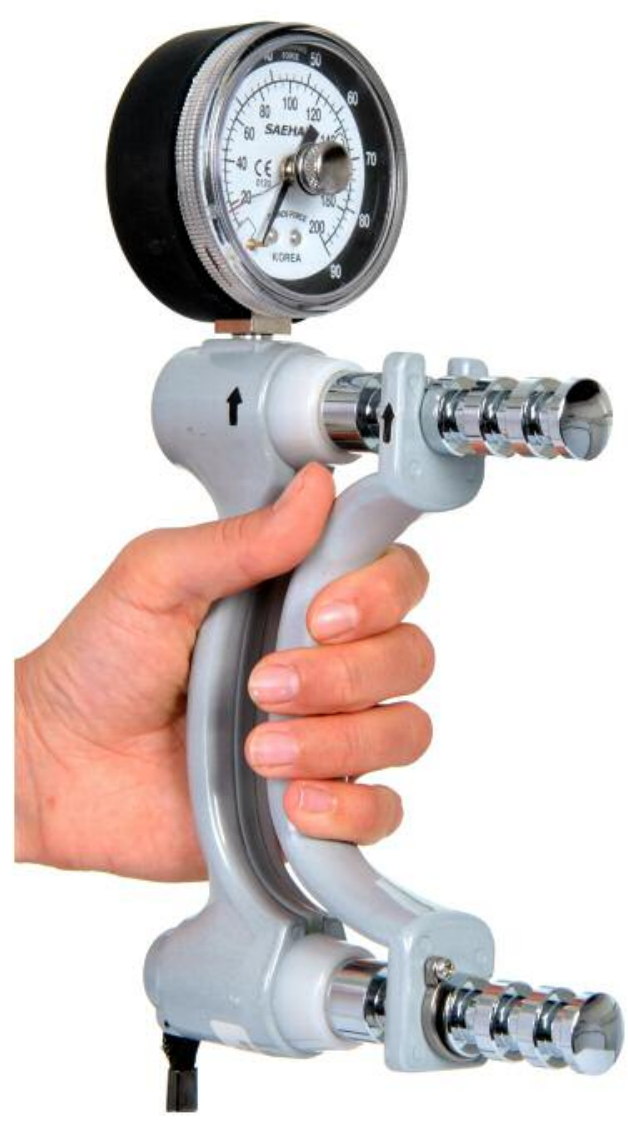

B

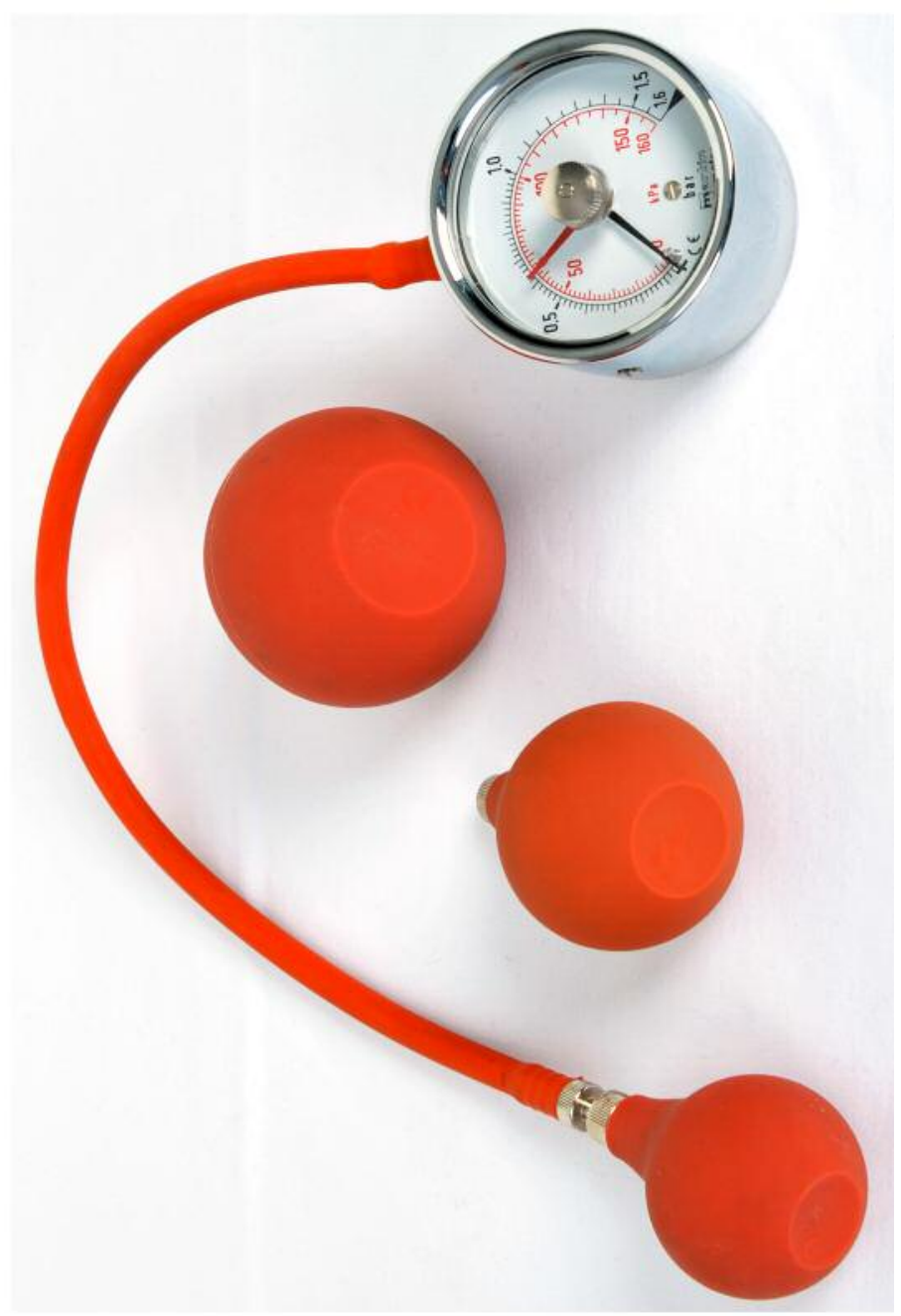

Figure 1. A. The JAMAR-Dynamometer is a hydraulic instrument measuring the isometric strength in kilogram. B. The Martin-Vigorimeter measures the force of compression in kilo pascal by means of a compressible rubber ball.

using notch 2 of the JAMAR-Dynamometer irrespective of the sex. At notch 3 of the JAMAR-Dynamometer, $31 \%$ of male and $16 \%$ of female patients achieved the highest results. Using the Martin-Vigorimeter, the highest results were achieved with balloon size 3 notwithstanding the sex (Figure 3 ). Overall, the age group 20-40 years showed the highest measured results for the grip strength regardless of the notch/balloon size (Figure 3).

\section{Discussion}

In this study, we examined 339 randomly selected patients with healthy hands to determine the correlations between all notches and balloon sizes for the Martin-Vigorimeter and the JAMARDynamometer. All 28 comparisons of the notches and balloon sizes showed moderate to very strong correlations. Within the instrument groups, the strongest correlations were found between the measured results of the JAMAR-Dynamometer notch 3 and notch 4 and Martin-Vigorimeter balloon size 3 and 5. Matching the results of both groups, the highest correlations were found between notches 2 and 3 of the JAMARDynamometer and balloon size 5 of the Martin-Vigorimeter. The lowest correlation was found between notch 5 of the JAMAR-Dynamometer and balloon size 2 of the MartinVigorimeter. These results can be explained by the large distance of approximately $90 \mathrm{~mm}$ between the handles of the 
in vivo $31: 917-924(2017)$

Table I. Demographic characteristics, Handedness and profession in all study participants.

\begin{tabular}{|c|c|c|c|c|}
\hline Demographics & Female $(n=132)$ & Male $(n=207)$ & $p$-Value & Whole collective \\
\hline Age (years) & $48.8 \pm 17.5^{*}$ & $49.1 \pm 19.0 *$ & $p>0.05$ & $49 \pm 18.4$ \\
\hline Gender $[\mathrm{n}(\%)]$ & $132(39 \%)$ & $207(61 \%)$ & $p>0.05$ & $339(100 \%)$ \\
\hline \multicolumn{5}{|l|}{ Handedness } \\
\hline Right-handed [n (\%)] & $125(95 \%)$ & $185(89 \%)$ & $p>0.05$ & $310(91,45 \%)$ \\
\hline Left-handed [n (\%)] & $4(3 \%)$ & $17(8 \%)$ & $p>0.05$ & $21(6,19 \%)$ \\
\hline Ambidextrous [n (\%)] & $3(2 \%)$ & $5(2 \%)$ & $p>0.05$ & $8(2,36 \%)$ \\
\hline \multicolumn{5}{|l|}{ Profession } \\
\hline Not specified [n (\%)] & $25(19 \%)$ & $39(19 \%)$ & $p>0.05$ & $64(19 \%)$ \\
\hline Easy manual work $[\mathrm{n}(\%)]$ & $90(68 \%)$ & $118(57 \%)$ & $0.039 * *$ & $208(61 \%)$ \\
\hline Moderate manual work [n (\%)] & $14(11 \%)$ & $14(7 \%)$ & $p>0.05$ & $28(8 \%)$ \\
\hline Hard manual work $[\mathrm{n}(\%)]$ & $4(3 \%)$ & $37(18 \%)$ & $p<0.001 * *$ & $41(12 \%)$ \\
\hline Retired $[\mathrm{n}(\%)]$ & $43(33 \%)$ & $72(35 \%)$ & $p>0.05$ & $115(34 \%)$ \\
\hline
\end{tabular}

$*$ Data are expressed as mean \pm SD. $* *$ Significant $(p<0.05)$

Table II. Correlation coefficients JAMAR-Martin .

\begin{tabular}{|c|c|c|c|c|}
\hline & Martin 2 & Martin 3 & Martin 5 & JAMAR 1 \\
\hline Martin 2 & $\mathrm{r}=1$ & $\mathrm{r}=0.87(0.84-0.90) p<0.001$ & $\mathrm{r}=0.80(0.76-0.84) p<0.001$ & $\mathrm{r}=0.70(0.64-0.75) p<0.001$ \\
\hline Martin 3 & $\mathrm{r}=0.87(0.84-0.90) p<0.001$ & $\mathrm{r}=1$ & $\mathrm{r}=0.92(0.90-0.93) p<0.001$ & $\mathrm{r}=0.74(0.69-0.79) p<0.001$ \\
\hline Martin 5 & $\mathrm{r}=0.80(0.76-0.84) p<0.001$ & $\mathrm{r}=0.92(0.90-0.93) p<0.001$ & $\mathrm{r}=1$ & $\mathrm{r}=0.73(0.68-0.78) p<0.001$ \\
\hline JAMAR 1 & $\mathrm{r}=0.70(0.64-0.75) p<0.001$ & $\mathrm{r}=0.74(0.69-0.79) p<0.001$ & $\mathrm{r}=0.73(0.68-0.78) p<0.001$ & $\mathrm{r}=1$ \\
\hline JAMAR 2 & $\mathrm{r}=0.70(0.63-0.75) p<0.001$ & $\mathrm{r}=0.79(0.75-0.83) p<0.001$ & $\mathrm{r}=0.86(0.83-0.89) p<0.001$ & $\mathrm{r}=0.86(0.82-0.88) p<0.001$ \\
\hline JAMAR 3 & $\mathrm{r}=0.67(0.60-0.72) p<0.001$ & $\mathrm{r}=0.78(0.73-0.82) p<0.001$ & $\mathrm{r}=0.86(0.82-0.88) p<0.001$ & $\mathrm{r}=0.81(0.77-0.84) p<0.001$ \\
\hline JAMAR 4 & $\mathrm{r}=0.67(0.60-0.72) p<0.001$ & $\mathrm{r}=0.77(0.72-0.81) p<0.001$ & $\mathrm{r}=0.85(0.81-0.87) p<0.001$ & $\mathrm{r}=0.81(0.74-0.82) p<0.001$ \\
\hline \multirow[t]{2}{*}{ JAMAR 5} & $\mathrm{r}=0.63(0.56-0.69) p<0.001$ & $\mathrm{r}=0.73(0.67-0.78) p<0.001$ & $\mathrm{r}=0.82(0.78-0.85) p<0.001$ & $\mathrm{r}=0.78(0.74-0.82) p<0.001$ \\
\hline & JAMAR 2 & JAMAR 3 & JAMAR 4 & JAMAR 5 \\
\hline Martin 2 & $\mathrm{r}=0.70(0.63-0.75) p<0.001$ & $\mathrm{r}=0.67(0.60-0.72) p<0.001$ & $\mathrm{r}=0.67(0.60-0.72) p<0.001$ & $\mathrm{r}=0.63(0.56-0.69) p<0.001$ \\
\hline Martin 3 & $\mathrm{r}=0.79(0.75-0.83) p<0.001$ & $\mathrm{r}=0.78(0.73-0.82) p<0.001$ & $\mathrm{r}=0.77(0.72-0.81) p<0.001$ & $\mathrm{r}=0.73(0.67-0.78) p<0.001$ \\
\hline Martin 5 & $\mathrm{r}=0.86(0.83-0.89) p<0.001$ & $\mathrm{r}=0.86(0.83-0.89) p<0.001$ & $\mathrm{r}=0.85(0.81-0.87) p<0.001$ & $\mathrm{r}=0.82(0.78-0.85) p<0.001$ \\
\hline JAMAR 1 & $\mathrm{r}=0.86(0.82-0.88) p<0.001$ & $\mathrm{r}=0.81(0.77-0.84) p<0.001$ & $\mathrm{r}=0.81(0.74-0.82) p<0.001$ & $\mathrm{r}=0.78(0.74-0.82) p<0.001$ \\
\hline JAMAR 2 & $\mathrm{r}=1$ & $\mathrm{r}=0.97(0.96-0.98) p<0.001$ & $\mathrm{r}=0.95(0.94-0.96) p<0.001$ & $\mathrm{r}=0.92(0.90-0.94) p<0.001$ \\
\hline JAMAR 3 & $\mathrm{r}=0.97(0.96-0.98) p<0.001$ & $\mathrm{r}=1$ & $\mathrm{r}=0.97(0.97-0.98) p<0.001$ & $\mathrm{r}=0.95(0.94-0.96) p<0.001$ \\
\hline JAMAR 4 & $\mathrm{r}=0.95(0.94-0.96) p<0.001$ & $\mathrm{r}=0.97(0.97-0.98) p<0.001$ & $\mathrm{r}=1$ & $\mathrm{r}=0.97(0.97-0.98) p<0.001$ \\
\hline JAMAR 5 & $\mathrm{r}=0.92(0.90-0.94) p<0.001$ & $\mathrm{r}=0.95(0.94-0.96) p<0.001$ & $\mathrm{r}=0.97(0.97-0.98) p<0.001$ & $\mathrm{r}=1$ \\
\hline
\end{tabular}

Correlation coefficient is rated as low $(\mathrm{r}<0.5)$, moderate $(\mathrm{r}<0.7)$, high $(\mathrm{r}<0.9)$, and very high $(\mathrm{r}>0.9)$. Martin: Martin-Vigorimeter; JAMAR: JAMARDynamometer.

JAMAR-Dynamometers at notch 5 . We believe that patients with small hands were unable to fully clasp the instrument and therefore could not make use of their full strength while the small balloon of the Martin-Vigorimeter is easily compressed irrespective of hand sizes. These results correspond to the findings of Espana-Romero et al., who showed a very strong correlation between the grip strength and the setting of the JAMAR-Dynamometer and patient hand size (21). Ruiz et al.
(22) also recommended determining the position of the notch of the JAMAR-Dynamometer according to a patient's hand size. Therefore, it must be assumed that the correlation coefficient of the individual positional settings of each instrument would be smaller if there was a high anatomical variance of the patients' hands sizes in the study group.

Regarding the weak correlations, the anatomical variance of our patients' study group allowed no prediction of the 

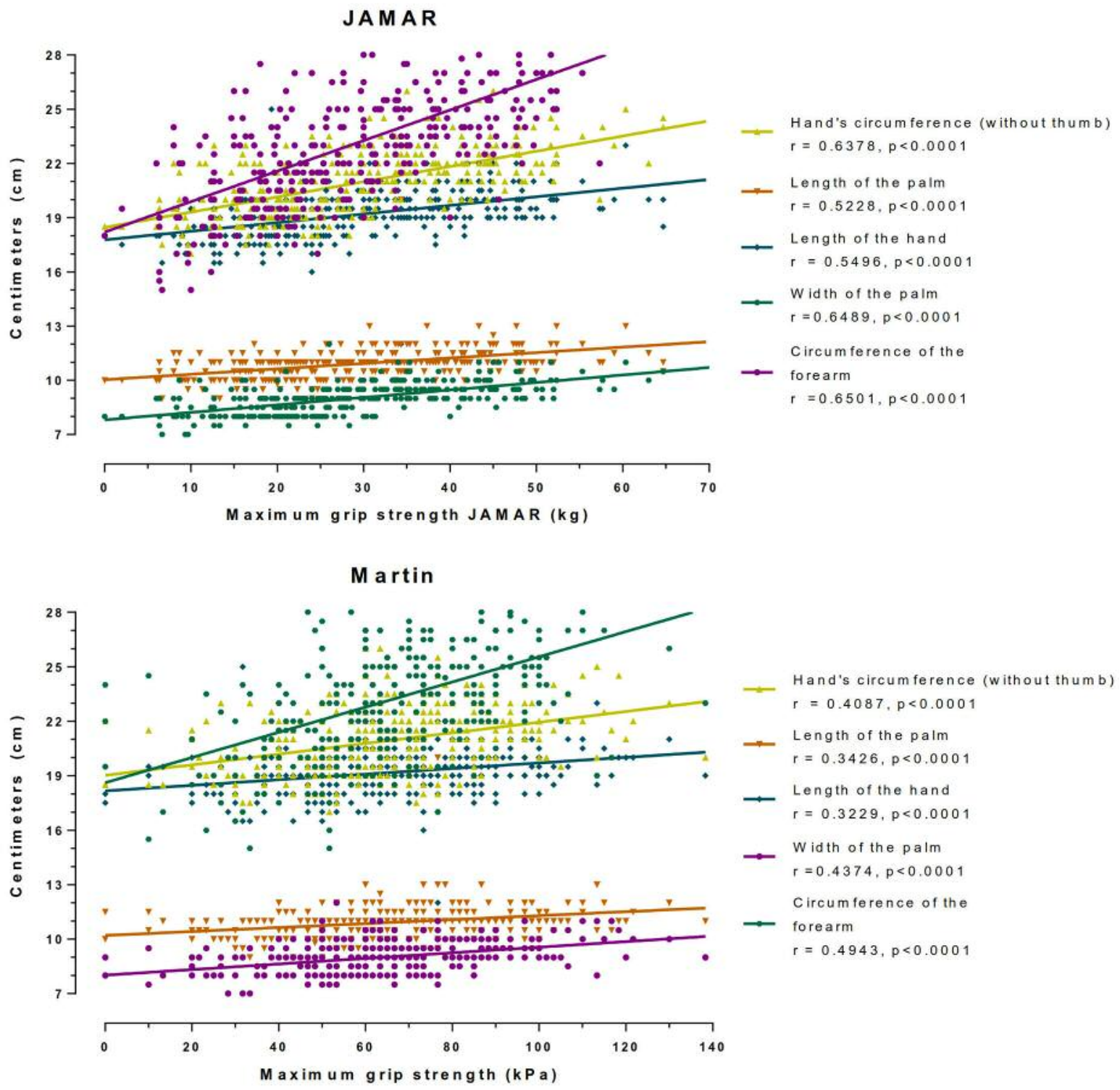

Figure 2. Graph shows the correlation between the influence of anatomical characteristics of the patient's forearm and hand with the maximum grip strength measured with the JAMAR-Dynamometer and the Martin-Vigorimeter.

Table III. Conversion table JAMAR-Martin.

\begin{tabular}{|c|c|c|c|c|c|c|c|c|}
\hline Data/Result & Martin 2 & Martin 3 & Martin 5 & JAMAR 1 & JAMAR 2 & JAMAR 3 & JAMAR 4 & JAMAR 5 \\
\hline Martin 2 & 1 & $1.15(\mathrm{SD} 0.2)$ & $0.83(\mathrm{SD} 0.3)$ & $5.59(\mathrm{SD} 5.8)$ & $2.21(\mathrm{SD} 0.8)$ & $2.39(\mathrm{SD} 1.0)$ & $2.89(\mathrm{SD} 1.5)$ & $4.25(\mathrm{SD} 4.6)$ \\
\hline Martin 3 & 0.90 (SD 0.2) & 1 & 0.73 (SD 0.2) & $6.30($ SD 7.7) & $2.43(\mathrm{SD} 0.8)$ & $2.62(\mathrm{SD} 0.9)$ & 3.17 (SD 1.5) & 4.78 (SD 5.6) \\
\hline Martin 5 & $1.34(\mathrm{SD} 0.5)$ & $1.47(\mathrm{SD} 0.4)$ & 1 & $4.42(\mathrm{SD} 5.6)$ & $1.68(\mathrm{SD} 0.5)$ & $1.8(\mathrm{SD} 0.5)$ & $2.13(\mathrm{SD} 0.7)$ & $2.93(\mathrm{SD} 1.5)$ \\
\hline JAMAR 1 & $0.26(\mathrm{SD} 0.1)$ & $0.23(\mathrm{SD} 0.1)$ & $0.32(\mathrm{SD} 0.1)$ & 1 & $0.51(\mathrm{SD} 0.2)$ & 0.55 (SD 0 & $0.64(\mathrm{SD} 0.3)$ & $0.86(\mathrm{SD} 0.4)$ \\
\hline JAMAR 2 & $0.52(\mathrm{SD} 0.2)$ & $0.46(\mathrm{SD} 0.2)$ & $0.65(\mathrm{SD} 0.2)$ & 2.59 (SD 2.5) & 1 & 1.09 (SD 0.2) & $1.29(\mathrm{SD} 0.3)$ & $1.86(\mathrm{SD} 1.5)$ \\
\hline JAMAR 3 & 0.49 (SD 0.2) & $0.43(\mathrm{SD} 0.3)$ & $0.61(\mathrm{SD} 0.2)$ & $2.48(\mathrm{SD} 2.7)$ & $0.94(\mathrm{SD} 0.1)$ & 1 & $1.19(\mathrm{SD} 0.2)$ & $1.71(\mathrm{SD} 1.3)$ \\
\hline JAMAR 4 & $0.42(\mathrm{SD} 0.2)$ & $0.37(\mathrm{SD} 0.2)$ & $0.52(\mathrm{SD} 0.2)$ & $2.08(\mathrm{SD} 2.1)$ & $0.81(\mathrm{SD} 0.2)$ & $0.86(\mathrm{SD} 0.2)$ & 1 & $1.39(\mathrm{SD} 0.7)$ \\
\hline JAMAR 5 & 0.33 (SD 0.2) & 0.29 (SD 0.2) & 0.40 (SD 0.2) & $1.63(\mathrm{SD} 1.8)$ & 0.63 (SD 0.2) & 0.67 (SD 0.2) & 0.77 (SD 0.2) & 1 \\
\hline
\end{tabular}

Data are given as conversion factors $\pm \mathrm{SD}$ for all values and all notches. Martin: Martin-Vigorimeter; JAMAR: JAMAR-Dynamometer. 

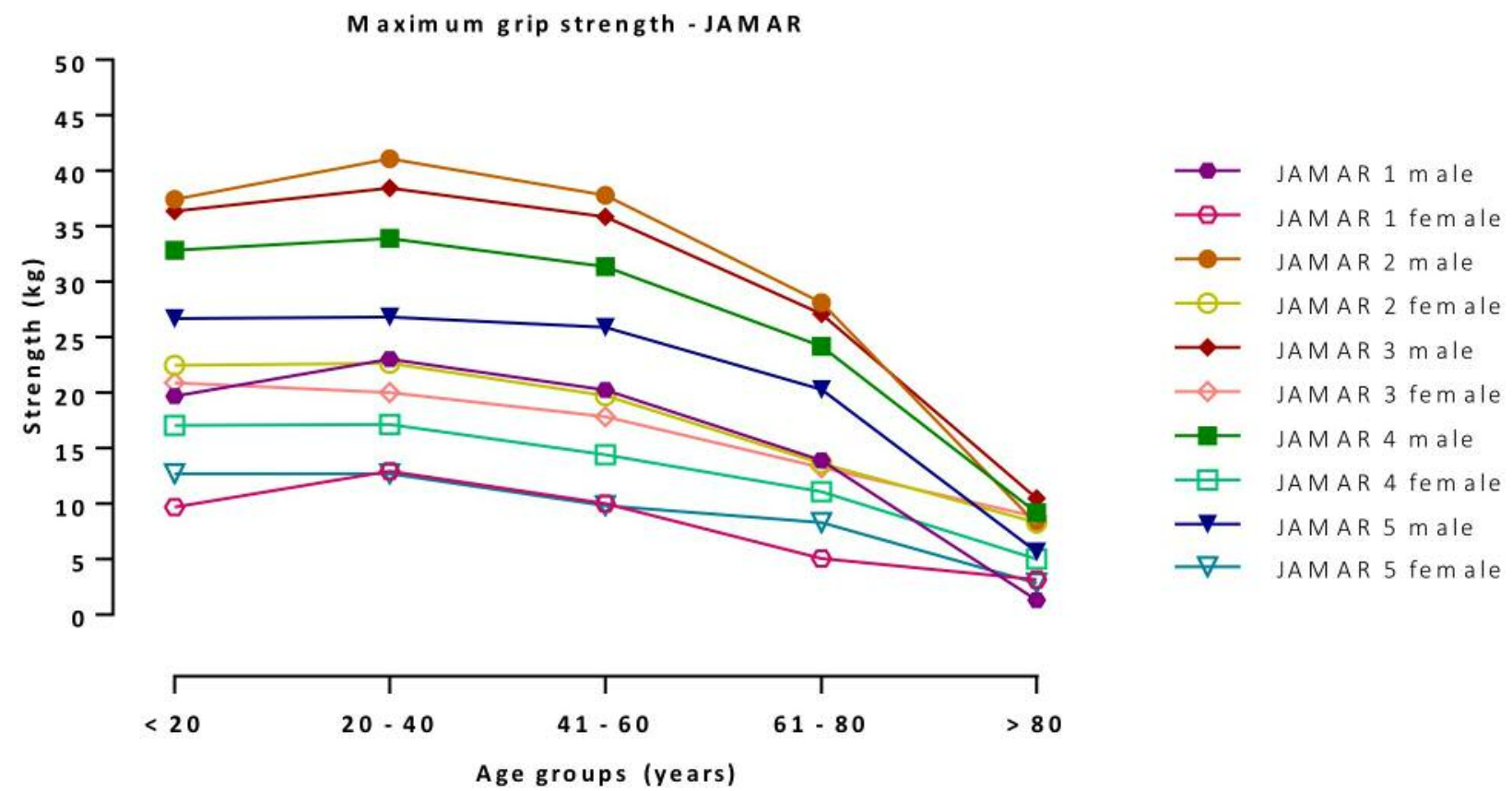

Maximum grip strength - Martin

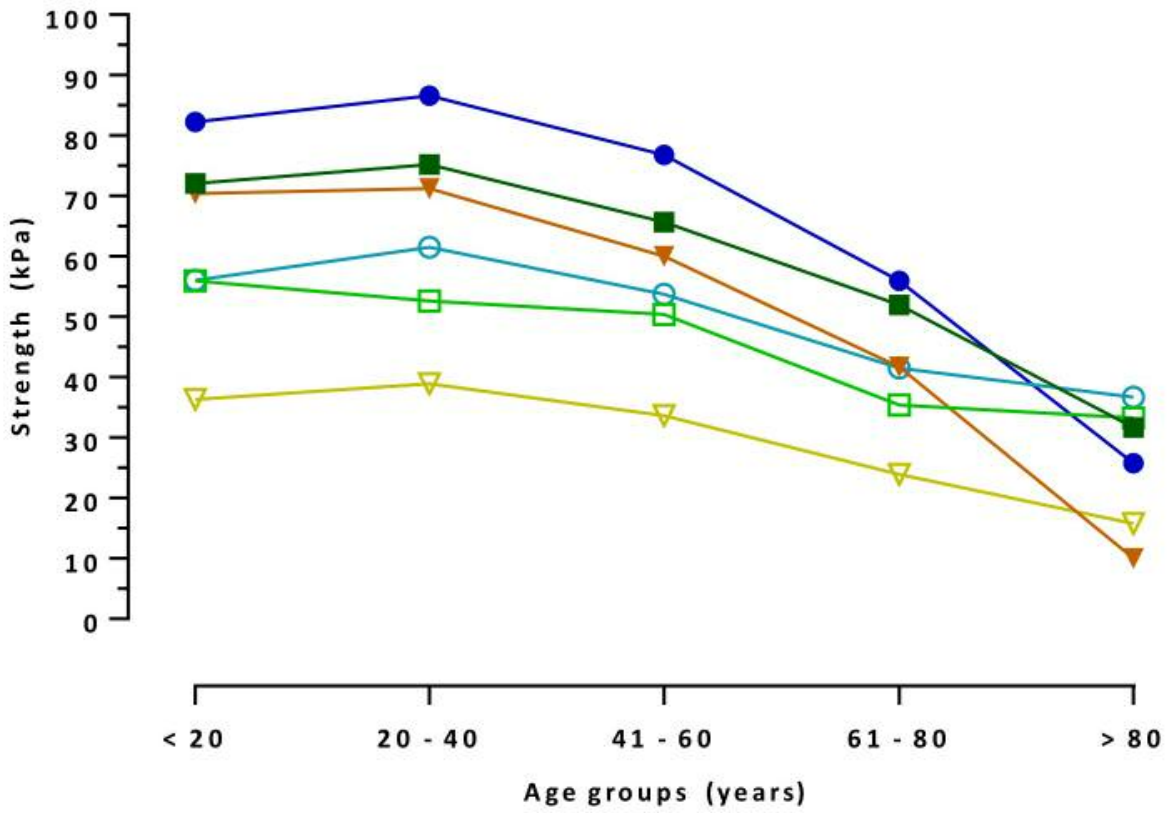

Figure 3. Graph shows the correlation between the influence of the patient's age and sex with the maximum grip strength measured with the JAMARDynamometer and the Martin-Vigorimeter.

maximal grip strength using the Martin-Vigorimeter. The results of Desrosiers et al. (13) and Li et al. (17) confirm our observation that the correlation between maximal grip strength and anatomical parameters is lower when using the
Martin-Vigorimeter than when using the JAMARDynamometer. In this study, the results of the maximal grip strength that were measured using the JAMARDynamometer showed the highest correlation with the width 
of the palm and the circumference of the forearm on the dominant side. At this point, our results are consistent with the current literature $(13,19,23,24)$. However, regarding the length of the hand, the literature presents inconsistent results. Our results show moderate correlation between grip strength and length of the hand and correspond to Li et al. (17). In contrast to these findings, the results of Boadella et al. (25) and Trampisch et al. (26) displayed either no correlation or merely a positive trend between grip strength and length of the hands/fingers and width of the hand and recommended standardised instrument settings. Ruiz-Ruiz et al. (27) found a correlation between hand size and strength in the female study group, but not in the male one. The inconsistent and partly contradictory results of the literature and our findings suggest that the influence of the anatomic variables on the grip strength is not significant and that anatomical factors will only influence the results when patients with small hands use settings with a large distance between the handles. We therefore concluded that anatomical factors alone should not determine the instrument's setting. Our results showed the highest grip strength for the JAMAR-Dynamometer on notch 2 and 3 and balloon size 3 for the Martin-Vigorimeter. These findings, as well as the strong correlation between the instruments indicate that measurements should be carried out on notch 2 and 3 with the JAMAR-Dynamometer and on balloon size 3 on the Martin-Vigorimeter. Settings for patients with either very large or very small hands should be adapted accordingly.

Similar to our findings of maximum grip strength for female and male patients in the age group of 20-40 years, Mathiowetz et al. (15) observed a peak of grip strength between the ages of 25 and 39 years, which slowly decreased thereafter. In the present study, the lowest strength was found in the group of patients $>80$ years, regardless of the sex of a patient. Tyler et al. (28) noticed that patients with weak hands had problems or were unable to use the JAMARDynamometer properly. Our study supports these findings since much older patients had difficulties handling this instrument due to its rigidity and weight. This could indicate that false low results could occur in older or sicker patients and that the correlation with the results of the MartinVigorimeter, which is easier to handle, decreases as a result.

Limitations to our study include the following: The evaluated instruments are primarily used on patients that have been deliberately excluded from this trial. We tried to minimize any measurement errors concerning the conversion factors by eliminating unpredictable results in an unhealthy population. The majority of the comparisons conducted in our study are already available in the current literature but, to our knowledge, this is the first study that correlates the two instruments in all available settings and determines conversion factors for the results of the JAMARDynamometer and the Martin-Vigorimeter. The conversion factors will allow us to compare studies with similar populations that use either one instrument in any setting and therefore add more data for eventual meta-analyses for hand surgical questions.

\section{Acknowledgements}

The Authors would like to express their deepest gratitude to Koko Kwisda, Jasjote Grewal and Courtney Metz for their revision and translation of the manuscript. The Authors also wish to thank Jan Beneke for his assistance in the statistical analysis.

\section{References}

1 Sipers WM, Verdijk LB, Sipers SJ, Schols JM and van Loon LJ: The martin vigorimeter represents a reliable and more practical tool than the jamar dynamometer to assess handgrip strength in the geriatric patient. J Am Med Dir Assoc 17(5): 466e461-467, 2016.

2 Bohannon RW and Schaubert KL: Test-retest reliability of gripstrength measures obtained over a 12-week interval from community-dwelling elders. J Hand Ther 18(4): 426-428, 2005.

3 Incel NA, Ceceli E, Durukan PB, Erdem HR and Yorgancioglu ZR: Grip strength: Effect of hand dominance. Singapore Med J 43(5): 234-237, 2002.

4 Bellace JV, Healy D, Besser MP, Byron T and Hohman L: Validity of the dexter evaluation system's jamar dynamometer attachment for assessment of hand grip strength in a normal population. J Hand Ther 13(1): 46-51, 2000.

5 Funfgeld EW: The vigorimeter: For measurement of the strength of the hand and simulation testing. Dtsch Med Wochenschr 91(49): 2214-2216, 1966.

6 Link L, Lukens S and Bush MA: Spherical grip strength in children 3 to 6 years of age. Am J Occup Ther 49(4): 318-326, 1995.

7 Mathiowetz V: Comparison of rolyan and jamar dynamometers for measuring grip strength. Occup Ther Int 9(3): 201-209, 2002.

8 Mathiowetz V, Weber K, Volland G and Kashman N: Reliability and validity of grip and pinch strength evaluations. J Hand Surg Am 9(2): 222-226, 1984.

9 Clerke AM, Clerke JP and Adams RD: Effects of hand shape on maximal isometric grip strength and its reliability in teenagers. J Hand Ther 18(1): 19-29, 2005.

10 Jones E, Hanly JG, Mooney R, Rand LL, Spurway PM, Eastwood BJ and Jones JV: Strength and function in the normal and rheumatoid hand. J Rheumatol 18(9): 1313-1318, 1991.

11 Solgaard S, Kristiansen B and Jensen JS: Evaluation of instruments for measuring grip strength. Acta Orthop Scand 55(5): 569-572, 1984.

12 Molenaar HM, Zuidam JM, Selles RW, Stam HJ and Hovius SE: Age-specific reliability of two grip-strength dynamometers when used by children. J Bone Joint Surg Am 90(5): 1053-1059, 2008.

13 Desrosiers J, Hebert R, Bravo G and Dutil E: Comparison of the jamar dynamometer and the martin vigorimeter for grip strength measurements in a healthy elderly population. Scand J Rehabil Med 27(3): 137-143, 1995.

14 Clifford MS, Hamer P, Phillips M, Wood FM and Edgar DW: Grip strength dynamometry: Reliability and validity for adults with upper limb burns. Burns 39(7): 1430-1436, 2013. 
15 Mathiowetz V, Kashman N, Volland G, Weber K, Dowe M and Rogers S: Grip and pinch strength: Normative data for adults. Arch Phys Med Rehabil 66(2): 69-74, 1985.

16 Mathiowetz V, Wiemer DM and Federman SM: Grip and pinch strength: Norms for 6- to 19-year-olds. Am J Occup Ther 40(10): 705-711, 1986.

17 Li K, Hewson DJ, Duchene J and Hogrel JY: Predicting maximal grip strength using hand circumference. Man Ther 15(6): 579$585,2010$.

18 Nicolay $\mathrm{CW}$ and Walker AL: Grip strength and endurance: Influences of anthropometric variation, hand dominance, and gender. Int J Ind Ergonom 35(7): 605-618, 2005.

19 Anakwe RE, Huntley JS and McEachan JE: Grip strength and forearm circumference in a healthy population. J Hand Surg Eur Vol 32(2): 203-209, 2007.

20 Mukaka MM: Statistics corner: A guide to appropriate use of correlation coefficient in medical research. Malawi Med J 24(3): 69-71, 2012.

21 Espana-Romero V, Artero EG, Santaliestra-Pasias AM, Gutierrez A, Castillo MJ and Ruiz JR: Hand span influences optimal grip span in boys and girls aged 6 to 12 years. J Hand Surg Am 33(3): 378-384, 2008.

22 Ruiz JR, España-Romero V, Ortega FB, Sjöström M, Castillo MJ and Gutierrez A: Hand span influences optimal grip span in male and female teenagers. J Hand Surg Am 31(8): 1367-1372, 2006.
23 Fraser A, Vallow J, Preston A and Cooper RG: Predicting 'normal' grip strength for rheumatoid arthritis patients. Rheumatology (Oxford) 38(6): 521-528, 1999.

24 Hemberal M, Doreswamy V and Rajkumar S: Study of correlation between hand circumference and maximum grip strength (mgs). Natl J Physiol Pharm Pharmacol 4(3): 195-197, 2014.

25 Boadella JM, Kuijer PP, Sluiter JK and Frings-Dresen MH: Effect of self-selected handgrip position on maximal handgrip strength. Arch Phys Med Rehabil 86(2): 328-331, 2005.

26 Trampisch US, Franke J, Jedamzik N, Hinrichs T and Platen P: Optimal jamar dynamometer handle position to assess maximal isometric hand grip strength in epidemiological studies. J Hand Surg Am 37(11): 2368-2373, 2012.

27 Ruiz-Ruiz J, Mesa JLM, Gutiérrez A and Castillo MJ: Hand size influences optimal grip span in women but not in men. J Hand Surg Am 27(5): 897-901, 2002.

28 Tyler H, Adams $\mathrm{J}$ and Ellis B: What can handgrip strength tell the therapist about hand function? J Hand Ther 18(4): 457, 2005.

Received July 25, 2017

Revised August 9, 2017

Accepted August 10, 2017 